\title{
Centenario del Servicio Geográfico Militar de Uruguay, 1913-2013
}

\author{
César Rodríguez Tomeo*
}

El Servicio Geográfico Militar (SGM) de Uruguay es la historia misma de los hombres y mujeres que lo integraron. Sacrificio, conocimiento y disciplina, jalonan los primeros 100 años. Su herramienta fundamental para la mejora continua, ha sido su gente, su férrea voluntad de hacer y de sobreponerse a los obstáculos. Ellos, generaron el legado, la tradición, a las que se suman las diferentes circunstancias y decisiones que debieron asumir, sus fortalezas y debilidades, sus aciertos y fallos,... los fallos que a todos, nos hace humanos.

La generación de productos y servicios de Información Geográfica, que necesita el usuario, es la razón de ser de éste organismo. Dicha información es una herramienta de planificación y ejecución, que no sólo es de aplicación en el concepto más puro de la Defensa Nacional, sino también un auxiliar del sector productor y de la sociedad toda.

Quienes nos precedieron nos dejaron un modelo de la realidad geográfica, cuyos hitos se materializan en la cartografía a escala 1:50,000 y 1:10,000 entre otras. Nos toca a nosotros, hacer los esfuerzos necesarios para hacer realidad la escala 1:25,000, que implica como primer paso, un nuevo vuelo fotogramétrico de la totalidad del país.

Día a día, la tecnología evoluciona a una velocidad que asombra. La Internet, el GPS y otras tecnologías, sobre cuyas bases se cimientan los productos y servicios cartográficos, facilitarán el uso, precisión, exactitud y fundamentalmente la actualización.

A pesar de los obstáculos, riesgos y temores a enfrentar, los que en su esencia son similares a los de ayer, nuestra actitud es de redoblar esfuerzos; dialogar y negociar, negociar y continuar dialogando. El objetivo es obtener la sinergía necesaria, entre todos los productores y usuarios de cartografía, donde la cooperación en el

* Director del Servicio Geográfico Militar de Uruguay. 
marco de la Infraestructura de Datos Espaciales sea la regla y no la excepción, a la cual atenerse.

La actividad fuera de fronteras no es ajena a esta Casa lo que implica integrar diversas comisiones y actividades académicas con otros organismos internacionales. Como prueba de ello recae sobre nuestros hombros la responsabilidad de organizar en el próximo mes de noviembre la 20 Asamblea General del Instituto Panamericano de Geografía e Historia en Montevideo. Es un reto que trasciende ampliamente al SGM y alcanza al nivel país, ya que pretendemos mostrar a todos los visitantes, una Nación pujante en todos los ámbitos, en particular en el área del conocimiento.

Con la finalidad de coordinar este prestigioso evento es que hemos tenido el honor de recibir al señor Secretario General del IPGH, M. Sc. Santiago Borrero Mutis, el cual fue invitado por el señor Director del SGM y Presidente de la Sección Nacional de Uruguay, coronel César Rodríguez, al lanzamiento del libro Historia del Servicio Geográfico Militar, que se llevó a cabo el 16 de mayo en la sede de esta Institución.

El libro fue escrito gracias a un importante trabajo de investigación, realizado en base a fuentes documentales relevantes y a los aportes de los protagonistas de la institución, ofreciendo una visión de la trascendente historia del SGM para la eternidad.

El señor Secretario General culminó la ceremonia de presentación haciendo uso de la palabra, agradeciendo la hospitalidad con que fue recibido en su primer visita a Uruguay. "He encontrado que el Uruguay es extremadamente cordial y eso me parece que habla mucho de la identidad de este país", expresó.
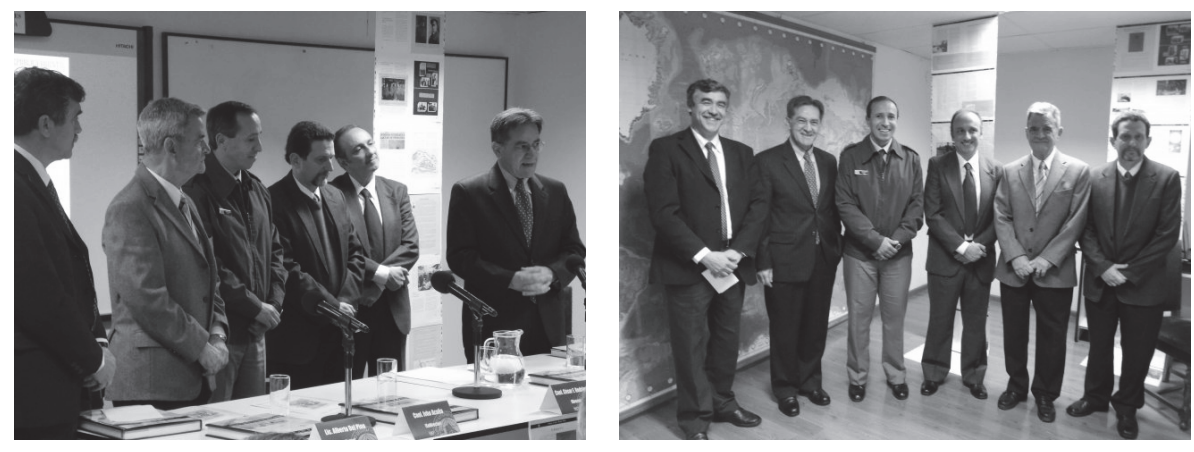

El SGM se aferra a lo que puede cambiar dejando de lado aquello que está fuera de su alcance. Esa actitud permite no solo ahorrar energía, sino focalizar la voluntad 
y capacidad de cambio, con el pragmatismo que indica que el pasado no se puede modificar, que con nuestro trabajo de hoy, se construye el futuro.

Hacia ese futuro avanza el SGM, con responsabilidad, procurando continuar por la senda que marcaron nuestros antecesores. Sorteando las incertidumbres que generan los cambios, con la amplitud mental de adaptarse a los mismos, pero fundamentalmente aferrándose a los valores que le dan razón de ser.

En el tercer milenio parece relevante volver a tomar conciencia de la pequeñez del hombre, tal como lo hicieron los antiguos romanos, Memento mori "recuerda que vas a morir", tal era la frase que se le reiteraba a los líderes victoriosos y cuyo objetivo era que no olvidaran las limitaciones de la naturaleza humana.

Tomando en cuenta esa pequeñez humana, ante el tiempo y las obras de quienes nos precedieron, el desafío es ser mejores cada día. El reto que nos impulsa es aportar a la sociedad un Servicio Geográfico Militar eficaz, eficiente y proyectado hacia el futuro. Para ello es necesario seguir trabajando con compromiso, practicidad y haciendo énfasis en la capacitación, para lograr aportar a la sociedad un trabajo técnicamente confiable y proyectado hacia el futuro.
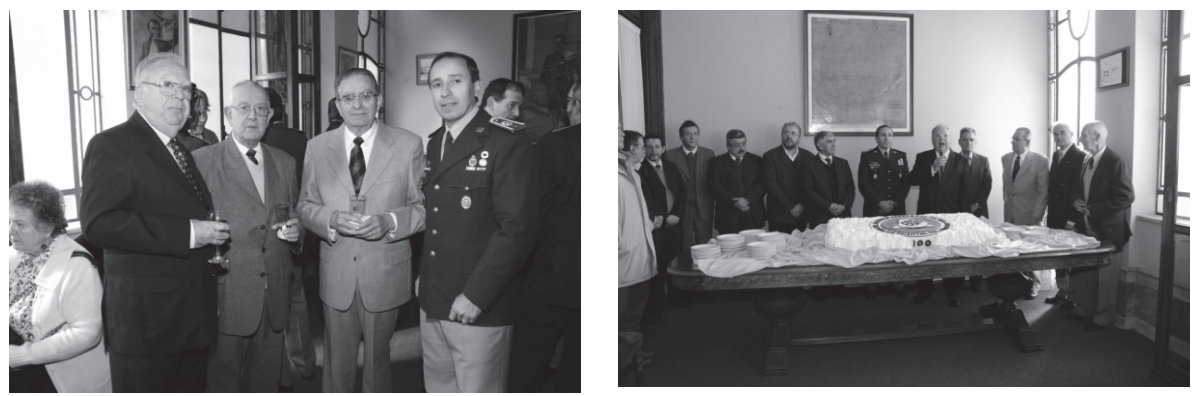

El Servicio Geográfico Militar, sede de la Sección Nacional uruguaya del IPGH, fue fundado el 30 de mayo de 1913. Su misión es la generación de productos y servicios de información geográfica de calidad.

Podemos expresar que si una frase sintetiza el sentimiento que nos embarga es que quienes forjaron los primeros 100 años del Servicio Geográfico Militar, sintieron pasión por lo que hacían e hicieron del sueño una realidad. 